\title{
Challenges of Amputees in Northern Ghana, a Low-Resourced Setting
}

\author{
Alexis D B Buunaaim ${ }^{1,2 *}$, Waliu Jawula Salisu ${ }^{3}$, Yempabe Tolgou ${ }^{4}$ and Hamdiyat Abdulai $\mathrm{S}^{5}$ \\ ${ }^{1}$ Department of Surgery, Trauma and Orthopedics Unit, Tamale Teaching Hospital, Ghana \\ ${ }^{2}$ Department of Surgery, School of Medicine and Health Sciences, University for Development Studies, Ghana \\ ${ }^{3}$ Department of Nursing, Tamale Teaching Hospital, Ghana \\ ${ }^{4}$ Department of Surgery, Trauma and Orthopedics Unit, Tamale Teaching Hospital, Ghana \\ ${ }^{5}$ Department of Research and development, Tamale Teaching Hospital, Ghana
}

Submission: September 24, 2020; Published: October 08, 2020

*Corresponding author: Dr. Alexis D B Buunaaim, Department of Surgery, Trauma and Orthopedics Unit, Tamale Teaching Hospital, School of Medicine and Health Sciences, University for Development Studies, Ghana

\section{Dear Editor,}

Amputations constitute a significant health burden and a source of multidirectional challenges to individuals, families, and health systems $[1,2]$. In recent times, diabetic complications have emerged as the leading cause of surgical amputations in many jurisdictions $[3,4]$. Post amputation, individuals may suffer a wide range of physical and psychological challenges. Adult amputees who live single lives may suffer more psychological distress than young children and married couples. Supportive partners are particularly useful in performing roles and supporting their amputee partners [2]. Our current study aimed to review the challenges of amputees following amputation surgeries, emphasizing the psychosocial challenges.
From January 2014 through to December 2016, we retrieved the case files of 112 patients who underwent amputation surgeries at the department of surgery, Tamale Teaching Hospital in Northern Ghana. All the patients had at least one amputation surgery and followed up for a minimum of two years post-surgery or death. Patients were excluded if they were below 18 years of age or had previously undergone any form of amputation. Ninetyone patients met the inclusion criteria. Of these, four patients were unwilling to participate, 25 could not be reached on the phone, and 18 had no valid phone numbers, leaving 44 in the study, Table 1.

Table 1: Patient characteristics.

\begin{tabular}{|c|c|}
\hline & Frequency \\
\hline Gender & $29(65.9 \%)$ \\
Male & $15(34.1 \%)$ \\
Female & $1(2.3 \%)$ \\
Age group & $10(22.7 \%)$ \\
19 years and below & $14(31.8 \%)$ \\
$20-40$ years & $6(13.6 \%)$ \\
$41-60$ years & $13(29.5 \%)$ \\
$61-70$ years & \\
71 and above & $5(11.4 \%)$ \\
Level of amputation & $39(88.6 \%)$ \\
Upper limb & \\
Lower limb & $10(22.7 \%)$ \\
\hline Indication for amputation & $4(9.1 \%)$ \\
Primary trauma & $30(68.2 \%)$ \\
\hline Complications from bonesetters & \\
\hline Diabetic foot & \\
\hline
\end{tabular}


The study had ethical approval from the ethical review board of Tamale Teaching Hospital.

We designed a questionnaire based on previous literature to assess the patient's general condition, including psychosocial issues post-surgery. Before commencement, the questionnaire was sent to two orthopedic surgeons for evaluation and inclusion of opinions-some adjustments were made afterward. Follow up telephone interviews were conducted using the self-developed questionnaire. First, the researchers introduced themselves and informed the patient/relative about the objectives of the study. Then, patients were asked if they were willing to participate. Those who gave consent and willing to participate were asked to respond to the questions objectively.

The data were analyzed using the Statistical Package for Social Sciences version 24. Only descriptive statistics were performed to highlight the frequencies and means of the variables. Fifteen $(34.1 \%)$ out of the total 44 were women. The ages of the participants ranged from 19 to 86, with 13 (29.5\%) being above 70 years of age. Most of the patients, 39 (88.6\%), underwent lower limb amputations. The main indications for surgery were diabetic complications 30 (68.2\%) and trauma 10 (22.7\%). At the time of the follow-up, $14(31.8 \%)$ of the patients had sadly died. Of the remaining $30(68.2 \%)$ who were alive, the majority $22(73.3 \%)$ confirmed that they could move around and carry out their usual activities post-surgery. Five (16.7\%) reported that they felt pain in the missing limb and amputation site. However, only $8(26.7 \%)$ used prosthesis. The main reason the majority $16(53.3 \%)$ cited for non-usage of the prosthesis was that they could not afford it. Others $8(26.7 \%)$ indicated that they did not know where to access prosthesis. Regarding the psychosocial dimension, 17 (56.7\%) agreed that they usually have memories of the incidents that led to their amputation surgeries. Also, 13 $(43.3 .5 \%)$ indicated that they had withdrawn from participating in most social activities since they last had their surgery done. 12 (40\%) participants agreed that their sexual life had been affected negatively by the surgery.

This brief analysis describes the challenges of surgical amputations and highlights the psychosocial effects patients experience post-amputation in a low-resource setting. Diabetic complications were disturbingly high among the study population, leading to a correspondingly high incidence of lower limb amputations. As a leading cause of non-trauma related amputations, diabetic complications impose a significant socioeconomic burden and contribute to a reduced quality of life among patients [5]. In this study, many participants died, affirming the devastating effects of diabetic complications, even post-surgery [6]. The rate of prosthesis usage among the study participants was low, confirming postulations in a previous study that access to prosthesis usage in most developing countries is limited [7].

The findings show that most participants are troubled by a range of psychosocial challenges arising from amputations. This could be due to the high number of participants being adults since their daily routines would be affected negatively. And possibly, the lack of psychological rehabilitation, which could lead to posttraumatic stress disorder (PTSD). This is in line with the findings of previous studies that show the challenges of psychological problems among amputees $[1,8]$. Also, since prosthetic use was minimal among the participants, a high degree of psychological challenges is expected.

Diabetic complications are fast becoming significant causes of amputation surgeries in the current study setting. Although prosthesis provides physical support and increases limb function, usage was minimal among the participants, mainly due to financial difficulties and lack awareness, and limited accessibility. This could have led to the widespread psychosocial burden in the study participants with the seemingly emerging PTSD. To minimize such debilitating effects on amputees, hospitals must set up rehabilitation centers to assist in the adaptation process for amputees.

\section{References}

1. Sahu A, Sagar R, Sarkar S, Sagar S (2016) Psychological effects of amputation: A review of studies from India. Ind Psychiatry J 25(1): 4-10.

2. Emotional and Psychological Reactions to Amputation - Physiopedia (2020).

3. Apelqvist J, Larsson J (2000) What is the most effective way to reduce incidence of amputation in the diabetic foot? Diabetes Metab Res Rev 16(S1): S75-83.

4. Kim J, Chun D Il, Kim S, Yang HJ, Kim JH, et al. (2019) Trends in lower limb amputation in patients with diabetic foot based on vascular intervention of peripheral arterial disease in Korea: A population-based nationwide study. J Korean Med Sci 34(26).

5. Shojaiefard A, Khorgami Z, Larijani B (2008) Independent risk factors for amputation in diabetic foot. Int J Diabetes Dev Ctries 28(2): 32-37.

6. Moulik PK, Mtonga R, Gill G V (2003) Amputation and mortality in new-onset diabetic foot ulcers stratified by etiology. Diabetes Care 26(2): 491-494.

7. Buunaaim D B A, Salisu W J, Tolgou Y, Abdulai S H (2019) Trauma-related amputations among children in Ghana. Journal of Surgery and trauma 7(4): 141-146.

8. Kawashita T, Dunnsiri T, Shu S, Tran P, Agustines D (2019) Losing Legs to Losing Everything: How Neglecting Holistic Health Devastated a Lower-limb Amputee. Cureus 11(12): e6275. 
Your next submission with Juniper Publishers will reach you the below assets

- Quality Editorial service

- Swift Peer Review

- Reprints availability

- E-prints Service

- Manuscript Podcast for convenient understanding

- Global attainment for your research

- Manuscript accessibility in different formats ( Pdf, E-pub, Full Text, Audio)

- Unceasing customer service

Track the below URL for one-step submission https://juniperpublishers.com/online-submission.php 